\title{
The CK1 gene family: expression patterning in zebrafish development
}

\author{
AMELINA ALBORNOZ ${ }^{*}$, JOSÉ M YÁÑEZ ${ }^{1 *}$, CLAUDIA FOERSTER $^{1}$, \\ CELESTE AGUIRRE ${ }^{1}$, LUISA PEREIRO ${ }^{1}$, VERÓNICA BURZIO ${ }^{2}$, \\ MAURICIO MORAGA ${ }^{1}$, ARIEL E REYES ${ }^{3,4}$ and MARCELO ANTONELLI ${ }^{1,3,4}$, **
}

\author{
${ }^{1}$ Instituto de Ciencias Biomédicas, Facultad de Medicina, Universidad de Chile, Independencia 1027, \\ Santiago, Chile. \\ 2 BiosChile, Avenida Marathon 1943, Santiago Chile. \\ ${ }^{3}$ Facultad Ciencias de la Salud, Universidad Diego Portales, Ejército 141, Santiago, Chile. \\ ${ }^{4}$ Millenium Nucleus in Developmental Biology, Departamento Biología, Facultad de Ciencias, Universidad \\ de Chile, Casilla 653 Santiago, Chile. \\ * These authors contributed equally to this work.
}

\begin{abstract}
Protein kinase CK1 is a ser/thr protein kinase family which has been identified in the cytosol cell fraction, associated with membranes as well as in the nucleus. Several isoforms of this gene family have been described in various organisms: $\mathrm{CK} 1 \alpha, \mathrm{CK} 1 \beta, \mathrm{CK} 1 \delta, \mathrm{CK} 1 \varepsilon$ and $\mathrm{CK} 1 \gamma$. Over the last decade, several members of this family have been involved in development processes related to wnt and sonic hedgehog signalling pathways. However, there is no detailed temporal information on the CK1 family in embryonic stages, even though orthologous genes have been described in several different vertebrate species. In this study, we describe for the first time the cloning and detailed expression pattern of five CK 1 zebrafish genes. Sequence analysis revealed that zebrafish CK1 proteins are highly homologous to other vertebrate orthologues. Zebrafish CK 1 genes are expressed throughout development in common and different territories. All the genes studied in development show maternal and zygotic expression with the exception of CK1 1 . This last gene presents only a zygotic component of expression. In early stages of development CK1 genes are ubiquitously expressed with the exception of CK $1 \varepsilon$. In later stages the five CK 1 genes are expressed in the brain but not in the same way. This observation probably implicates the CK1 family genes in different and also in redundant functions. This is the first time that a detailed comparison of the expression of CK 1 family genes is directly assessed in a vertebrate system throughout development.
\end{abstract}

Key terms: CK1, Casein Kinase 1, Expression pattern, Development, Zebrafish, otic vesicles, retina, lens, pectoral fin bud, tegmentum, myelencephalon, telencephalon, diencephalon, mesencephalon, rhombomeres.

\section{INTRODUCTION}

Protein kinase CK1 is a ser/thr protein kinase which has been identified in the cytosol cell fraction, associated with membranes as well as in the nucleus. A cellcycle-dependent localization to mitotic spindles of dividing cells has also been reported (Vielhaber and Virshup, 2001; Knippschild et al., 2005) Identification of cDNAs encoding vertebrate $\mathrm{CK} 1$ has revealed seven isoforms to date: $\mathrm{CK} 1 \alpha$ (casein kinase 1, alpha 1), CK1 $\beta$ (casein kinase 1 , beta), CK1 $\delta$ (casein kinase 1 , delta), CK1 $\beta$ (casein kinase 1, epsilon) and three CK1 $\gamma$ (casein kinase 1, gamma 1-3) isoforms (Gross and Anderson, 1998; Burzio et al., 2002). Members of the CK1 family have been recently involved in developmental processes, associated to the wnt signalling pathway (Liu et al., 2002; Marin et al. 2003) and the sonic hedgehog pathway (Pan et al., 2006; Tempe et al., 2006). For example, CK1ع was recently shown to induce secondary axes in Xenopus laevis, stimulating $\beta$-catenin signalling, thus

\footnotetext{
** Corresponding author, Telephone: (56-2) 9786259; Fax: (56-2) 7376329; E-mail address: mantonel@med.uchile.cl (M. Antonelli)
} 
functioning in a manner that is opposite to that demonstrated for CK $1 \alpha$ (Liu et al., 2002; Cong et al., 2004). This last isoform is essential for $\beta$-catenin phosphorylation in a priming mechanism that also involves GSK3 and which is required for $\beta$-catenin degradation (Liu et al., 2002).

Zebrafish have emerged as a powerful model system to study development, due to their external development, transparency of embryos and the availability of mutants, transgenic lines and gene knock-down technology (Lewis and Eisen, 2003; Lee and Chien, 2004). To further the study of CK1 family genes in early zebrafish development we are reporting in this communication the cloning of four CK1 isoforms: CK $1 \varepsilon$

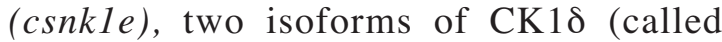
csnkld-a and csnkld-b) and one isoform of CK1 $\gamma$-2 (csnk1g2). We also described their mRNA expression by RT-PCR and by in situ hybridization and included in our studies the expression patterning of the previously cloned zebrafish $\mathrm{CK} 1 \alpha$ isoform (Burzio et al., 2002). The expression patterns of these genes for the first two days of the zebrafish embryonic life are presented.

\section{MATERIAL AND METHODS}

\section{Animals}

Zebrafish embryos were raised according to standard procedures (Westerfield, 1995) and staged in hours post-fertilization according to Kimmel et al. (1995). All embryos were collected by natural spawning, Kimmel et al. (1995) and were raised at $28^{\circ} \mathrm{C}$ in $\mathrm{E} 3$ medium $(5 \mathrm{mM} \mathrm{NaCl}, 0.17 \mathrm{mM} \mathrm{KCl}, 0.33$ $\mathrm{mM} \mathrm{CaCl} 2,0.33 \mathrm{mM} \mathrm{MgSO}_{4}$, and $0.1 \%$ methylene blue) in petri dishes (Haffter et al., 1996). Larval stages are expressed in hours postfertilization (hpf).

\section{Cloning of CK1 isoforms genes in zebrafish}

CK1 $\alpha$ (csnklal) was previously cloned as described by Burzio et al., 2002. The other CK1 genes were cloned by RT-PCR (Sambrook et al., 1989) from public database ESTs. Briefly, a 24 hour postfertilization zebrafish embryo cDNA library was synthesized by reverse transcription using oligo-dT primer and RNAse H (Sambrook et al., 1989). The library was used to amplify the CK1 genes by PCR using specific primers derived from zebrafish ESTs. Primers for CK $1 \varepsilon$ isoform (csnkle) were obtained from ESTs AW305656 and AW282083. For CK1 $\gamma$-2a isoform (csnklg2a), primers were derived from ESTs BM103034 and BM103881 and for the two sequences that coded for CK $1 \delta$ isoforms, $c \operatorname{snk} l d a$ and $c s n k l d b$, the primers were derived from ESTs BQ263495, AW174665, AW127719 and AW115550). Using this strategy we cloned a complete ORF of each of the zebrafish CK1 isoforms.

PCR primers were:

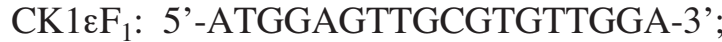
CK $1 \varepsilon R_{1}:$ 5'-GTCAACATACAACACTTTC TG-3;

CK1 $1 \mathrm{OaF}_{1}$ : 5'-AGGGCCAGCAGAACTAG GAAG-3;

CK1 $1 \mathrm{AR}_{1}$ : 5',-TCTCAAGTGTTGTTTAA TTGCAT-3';

CK $1 \delta b_{1}:$ 5'-ATGGAGCTACGAGTTGG AAAC-3';

CK $1 \delta b R_{1}$ : 5'-CACTGTTTAAAATACAC AAATACG-3';

CK $1 \gamma-2 \mathrm{aF}_{1}$ : 5'-ATGAGCATTAAAATCGA CCAAATG-3;

CK $1 \gamma-2 \mathrm{aR}_{1}$ : 5'-AGTGACTTTTAACGTTT CATTATGT-3'. ORFs were cloned in pCRIITopo (Invitrogen) or Bluescript (Stratagene). All the above clones were sequenced in both directions using an automated DNA Sequncer (CESAT facility, ICBM, Facultad de Medicina, Universidad de Chile) or manually (Sambrook et al., 1989). The CK1 cDNA cloned sequences were confirmed by independent PCR from three different cDNA libraries derived from mRNA obtained at 3, 10 and $24 \mathrm{hpf}$ zebrafish embryos. In the Ensemble database (www.ensembl.org/Danio_rerio) seven predicted zebrafish genes were found: The gene identification number ENSDARG00000007993 maps to chomosome 14 and codes for CK $1 \alpha$ isoform (Csnk1a1); ENSDARG00000055907 maps to chromosome 12 and codes for CK1E (Csnk1e); ENSDARG00000008370 maps to chromosome 3 and codes for $\mathrm{CK} 1 \delta a$ (Csnk1da); ENSDARG00000006125 maps 
to chromosome 12 and codes for CK1 $1 \delta$ (Csnk1db); ENSDARG00000005458 maps to chromosome 2 and codes for $\mathrm{CK} 1 \gamma-2 \mathrm{a}$ (Csnk1g2a); ENSDARG00000034056 maps to chromosome 8 and codes for CK $1 \gamma-2 b$ (Csnk1g2b); ENSDARG00000033872 maps to chromosome 7 and codes for $\mathrm{CK} 1 \gamma-1$ (Csnk1g1).

\section{Expression by $R T-P C R$}

To evaluate the expression of CK1 genes in embryos, RT-PCR was performed, with primers as follows: for CK $1 \alpha$ (amplified four fragments: CK1 $1 \alpha \mathrm{LS}$ : $748 \mathrm{pb}$; CK $1 \alpha \mathrm{L}$ : 712 pb; CK1 $1 \alpha \mathrm{S}$ : 664 pb; CK1 $\alpha 628$ bp) CK $1 \alpha F_{1}$ 5' - GCCGTCACTGTAATAA-3' and $\mathrm{CK} 1 \alpha \mathrm{R}_{1}$ 5'-TGGTGAATTTGATCCT AG-3'; for CK1ع (amplified fragment 780 bp) $\mathrm{CK} 1 \varepsilon \mathrm{F}_{2}$ 5'-GCTCTGCAACATCTCTG TCA-3' and CK1عR 2 5'-TACTTTGATAT GTGTGTTTATTTA-3'; for CK1 $\mathrm{\delta a}$ (amplified fragment $1003 \mathrm{bp}$ ) $\mathrm{CK} 1 \mathrm{\delta aF}_{2} 5^{\prime}$ GACCCTCCACACGCCTCA-3' and CK1סaR 2 5' - ACAGCATGGACTCAA CCACG-3'; for CK1 $1 \delta$ b (amplified fragment 1001 bp) CK1 $1 \delta b_{2}$ 5'-ATGCTCCTCACA

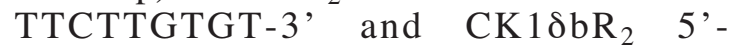
AAGAGTCAAAGTTCATGTTCAG-3'; for CK1 $\gamma$-2a (amplified fragment 512 bp) CK $1 \gamma-2 \mathrm{aF}_{2}$ 5'-ATGGATTTTGATAAGA GAGGAGG-3' and CK $1 \gamma-2 \mathrm{aR}_{2}$, 5'TTAACATCCCTGTAGATC-3';). mRNA was obtained using Trizol® Reagent according to the manufacturer's indications (Invitrogen, San Diego, CA, USA) from embryos at different stages of development $(3,4,6,9,12,24,48,72,144$ hpf $)$. RT was performed with the cDNA Cycle Kit (Invitrogen, San Diego, CA, USA) according to the manufacturers, instructions. As internal control we used $\beta$ actin primers: F1-5'-GACATCAGGGAGT GATGGTTG-3' and $\mathrm{R}_{1}-5$ ' - CTGACCGTC AGGCAGCTCATA-3' (amplified fragment $622 \mathrm{bp}$ ), as described previously (Chen et al., 2002; Mackenzie et al., 2004).

\section{Phylogenetic tree construction and protein alignment}

A neighbor-joining dendrogram was constructed, employing a Kimura 2- parameter distance matrix of Kimura (1980) as input. Phylogenetic trees were obtained through the neighbor-joining method (Saitou and Nei, 1987), employing the MEGA3.1 program (Kumar et al., 2004). Phylogenetic analysis was performed with 7 CK 1 zebrafish gene family members and 28 other CK1 genes from different species (Accession numbers H.sapiens CK1 family genes: CK1 $\alpha$ NM_001025105; CK1 $\delta$ BC003558; BC015775; CK1ع NM_152221; CK $1 \gamma-1$ NM_001011664; CK1 $\gamma$-2 BC018693; CK1 $\gamma$ 3 AF049090. M.musculus: CK $1 \alpha$ AK146873; CK1ס NM_027874; NM_139059; CK1ع BC026127; CK1 $1 \gamma-1$ NM_173185; CK1 $\gamma-2$ AK132871; CK1 $\gamma-3$ BC033601. X.laevis: CK1 $\alpha$ Y08817; CK1 $\delta$ AY926535; CK 1ع AF183394; CK $1 \gamma-1$ BC070639; CK1 $1 \gamma-2$ BC073708; CK $1 \gamma-3$ BC090234. X.tropicalis: CK1 $\alpha$ BC067926;

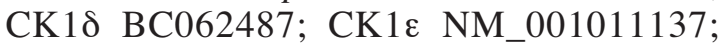
CK1 $\gamma$-1 CT030290; CK1 $\gamma-2$ BC089657; CK1 $\gamma-3$ BC090234. G.gallus: CK $1 \alpha$

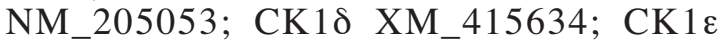
NM_204377; CK1 $\gamma$-1 NM_001005800. The accesion numbers of D.rerio cloned genes

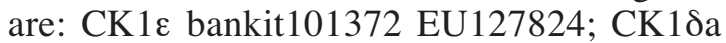
bankit1013757 EU127826; CK1 $\delta$ b bankit1013739 EU127825 and CK1 $\gamma-2 a$ bankit1013782 EU127827. Deduced amino acid sequences were aligned using Clustal method (Chenna et al., 2003).

Whole mount in situ hybridization and histology

Embryos were raised at $28{ }^{\circ} \mathrm{C}$ and fixed for in situ hybridization in $4 \%$ paraformaldehyde. Hybridizations were performed as previously described (Jowett and Lettice, 1994). Probes were designed to contain only the 3' UTR by using RT-PCR with the exception of the probe for CK $1 \gamma-2 \mathrm{a}$ that contain part of the 5'UTR and part of the coding region (see above). The probes contained $816 \mathrm{pb}, 780 \mathrm{pb}, 1003 \mathrm{pb}, 1001 \mathrm{pb}$ and $1036 \mathrm{pb}$ for $\mathrm{CK} 1 \alpha, \mathrm{CK} 1 \varepsilon, \mathrm{CK} 1 \delta \mathrm{a}$, $\mathrm{CK} 1 \delta \mathrm{b}$ and $\mathrm{CK} 1 \gamma-2 \mathrm{a}$, respectively (oligos for CK1 $\alpha$ PCR: CK $1 \alpha F_{2}$ 5'-GCATTAAGA CAATGTAATGAAGC-3' and CK $1 \alpha \mathrm{R}_{2} 5^{\prime}$ 'AGACTTCAGAATACCAAGTAC-3'; for CK $1 \varepsilon: \quad \mathrm{CK} 1 \varepsilon \mathrm{F}_{2}$, 5'-GCTCTGCAACAT

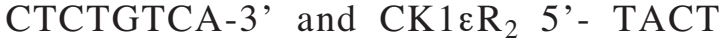


TTGATATGTGTGTTTATTTA-3'; for

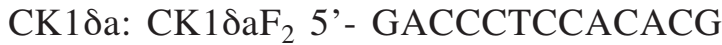
CCTCA-3' and CK1 $1 \mathrm{OR}_{2}$ 5'-ACAGCA TGGACTCAACCACG- 3'; for CK $1 \delta b$ : CK $1 \delta \mathrm{bF}_{2}$ 5'-ATGCTCCTCACATTCTT GTGT-3' and CK1 $1 \delta b R_{2}$ 5'- AAGAGTC AAAGTTCATGTTCAG-3'; for CK $1 \gamma-2 \mathrm{a}$ : CK $1 \gamma-2 \mathrm{aF}_{3} 5^{\prime}$ - TGAGCATTAAAATCG ACCAAA-3' and CK $1 \gamma-2 \mathrm{aR}_{2}$ 5' - TTAACA TCCCTGTAGATC-3';). Embryos were mounted in glycerol and photographs were taken with a Leica DC300F digital camera on a Leica MZ12.5 stereomicroscope or on a Nikon Eclipse 80i microscope. After in situ procedures, the embryos were post-fixed 20 minutes in $1.25 \%$ glutaraldehyde/ $2 \%$ paraformaldehyde in BT buffer $(0.15 \mathrm{mM}$ $\mathrm{CaCl}_{2}, 4 \%$ sucrose, $0.1 \mathrm{M}$ phosphate buffer (Westerfield, 1995), as described previously (Bever and Fekete, 2002). Embryos were then dehydrated in graded ethanol series, and embedded in Paraplast plus ${ }^{\circledR}$ (UK), followed by sectioning at $9 \mu \mathrm{m}$ and mounted in 3aminopropyltriethoxysilane (Polysciences, Inc., Washington, PA, USA) treated slides and stained with eosin.

\section{RESULTS}

\section{Cloning of zebrafish CK1 family genes}

To clone zebrafish CK1 isoforms we searched the zebrafish EST published libraries using as a virtual probe a zebrafish CK $1 \alpha$ (csnkla) cDNA derived from the coding region (Burzio et al., 2002; accession number NM_152951). To obtain the CK1 isoforms we used EST clones containing either full length or partial CK1 homologs, as well as PCR techniques where necessary. We found four cDNA sequences from four different CK1 family genes which we identified by their homology with mammalian CK1 orthologues. Two of the four cloned sequences were closely related to human CK1E (csnkle) isoform (ESTs AW305656 and AW282083) (A.N) and CK1 $1 \gamma$-2 (csnklg2a) isoform (ESTs BM103034 and BM103881) (A.N). The other two sequences were closely related to

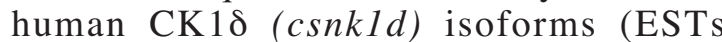
BQ263495, AW174665, AW127719 and AW115550) (A.N). These genes probably arose by a genome duplication in teleost fish (Amores et al., 2004; Chen et al., 2004) and were designated casein kinase 1, delta $a$ (csnkda) and casein kinase 1 , delta $b$ $(c s n k d b)$, in accordance with the zebrafish nomenclature for duplication genes (http:// zfin.org/zfinfo/ nomen.html). A neighborjoining dendrogram was constructed, employing a Kimura-2 distance parameter matrix as input (Kimura, 1980). Phylogenetic trees were obtained with known CK1 cDNAs (Fig. 1) from different vertebrate species, through this neighborjoining method (Saitou and Nei, 1987), employing the MEGA3.1 program (Kumar et al., 2004). Each one of the CK1 isoform families constitutes an exclusive branch with exception of CSNK1G2 in which X.tropicalis and X.laevis CK1 orthologues stay out of the clade. All the zebrafish CK1 genes segregated with their respective species homologues, as expected from pairwise comparisons. We also analyzed the zebrafish genome in the Ensembl database (http://www.ensembl.org/index.html) finding two more genes: one CK $1 \gamma-1$ (csnklgl) and a second gene for CK $1 \gamma-2$ (csnklg2). A CK1 $\gamma-3$ was not found in the zebrafish genome. A graphical alignment (Fig. 2) of amino acid sequences of zebrafish CK1s and human CK1 $\alpha$ (CSNK1A) shows the overall high degree of homology for CK1 family gene within and outside the serine/threonine protein kinase catalytic domain (Hanks and Hunter, 1995). Zebrafish cDNAs coded for proteins of 365-418 amino acids in length (Fig. 2) and BLAST analysis of the deduced sequence indicated highest similarities with specific human CK1 (98\% for Csnk1db, 93\% for Csnk1g2a, $91 \%$ for Csnk1da and $87 \%$ for Csnk1e). This homology is markedly higher than that of other zebrafish genes cloned and probably is a consequence of a very conserved function of these family genes throughout evolution (Schweeitzer et al., 2005). 


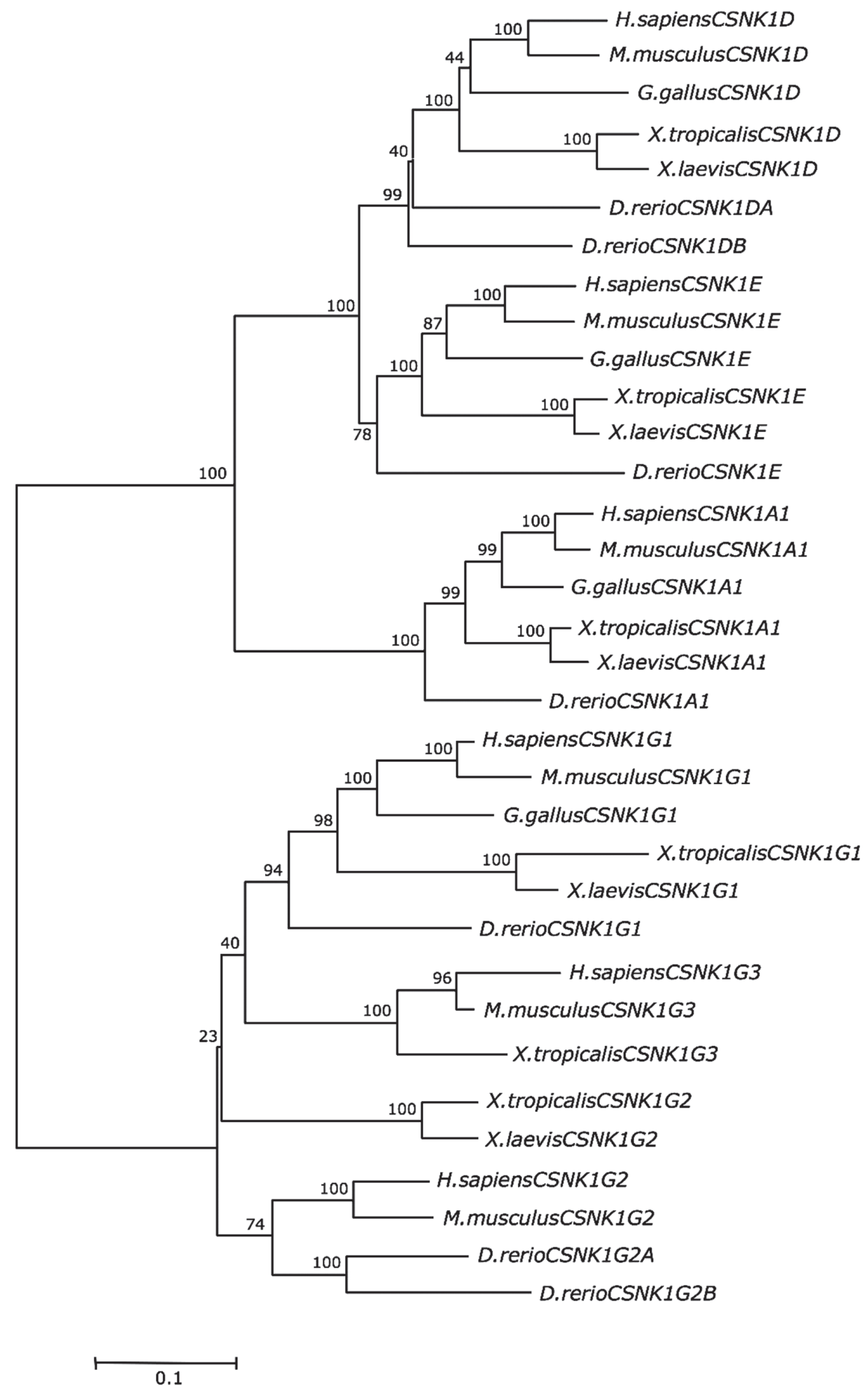

Fig. 1: Phylogenetic relationships of CSNK1 genes of D. rerio and other vertebrates. Sequences are from human (H. sapiens), mouse (M. musculus), chicken (G. gallus), zebrafish (D. rerio) and frog (X. laevis and X.tropicalis) D. rerio has two genes for CSNK1D and CSNK1G2 whereas the other species have only one. Bootstrap value of 500 iterations is shown at each node. Branch lengths are drawn to scale. 
hCK la lpha z fCKlalpha z fCK1 del ta - a z fCKldel ta $-b$ z fCKlepsilon z fCKl gamma - 2 a

hCKlalpha z fCK1alpha z fCK1del ta-a $z$ fCK1 del ta-b $z$ fCK1 epsilon z fCK1 g amma- 2 a

hCKlalpha z fCKlalpha zfCKldel ta-a z fCK 1 del ta $-b$ z fCK1 epsilon z fCK 1 gamma -2 a

hCKlalpha z fCKlalpha z fCK1del ta-a $z$ fCK1 del ta $-b$ z fCKlepsilon z fCK1 gamma - 2 a

hCK lalpha z fCKlalpha z fCK 1 del ta-a z fCK 1 del ta $-b$ z fCK1 epsilon z fCK1 gamma- 2 a

hCKlalpha z fCKlalpha zfCK1 del ta-a zfCKl del ta-b $z$ fCKlepsilon z fCK 1 gamma -2 a

hCK la lpha z fCKlalpha z fCK1del ta-a z fCK1 del ta-b $z$ fCK1 epsilon $\mathrm{z}$ fCK1 gamma - 2 a

hCKlalpha z fCKlalpha z fCKldelta-a z fCKldel ta-b z fCK1 epsilon z fCK 1 gamma-2a

hCKlalpha z fCK1 alpha z fCK 1 del ta-a z fCK1 del ta-b $z$ fCK1 epsilon z fCK 1 gamma - 2 a
1

1

1

1

1

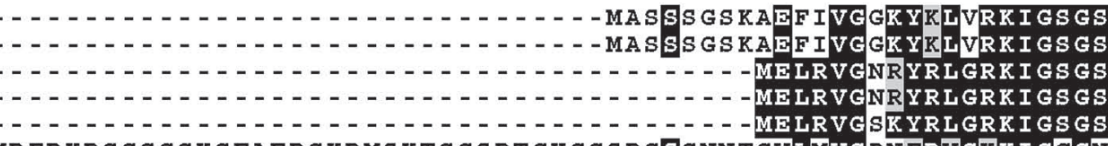

\section{FGDIYLA IN ITNGEEVAVKLES OKA RH PQLLYESKLYKI LQGGVG IPHTRWYGOEKDYNV FGDIYLGTDITTGEEVAIKLECVKTKHPOLHISKIYKMMOGGVGIPTIKWCGAEGDYNV FGDI YLGTDISVGEEVAIKLECVKTKH PQLH IESKIYKMMQGGVGI PTI KWCGAEGDYNV FGDIYLGANITSGEEVA I KLESVKTKH PQLHIESKFYKMMQGGVGI PSI KWCGA EGDYNV FGELRLGKNLYTNEYVA I K L E IKSRAPQLHLEYRFYKQLGNA EGVPQVYYFGPCGKYNA}

147 GRHCNKCLESPVGKRKRSMTVSTSQDPSF SGLNQLFLIDFGLAKKYRDNRTRQH IPYRED 147 GRHCNKCLES PVGKRKRS LAVS S QDP SF S G LNLFLI DFGLAKKYRDNRTRQH I P YRED 139 GKKG - . - . 139 GKKG - - - - - - - - - NLVYIIDFGLAKKYRDARTHQH I PYREN 139 GKKG - . 181 GTKR - . . . . . . . . . . . - QH T I HI I DFGLAKEYIDP ETKKH I P YREF

207 KNLTGTARYAS INAHLGIEQSRRDDMES LGYVLMYFNR TS LPWQGLR AA TKKOKYEKI SE 207 KNLTGTARYAS INAHLGI EQSRRDDMESLGYVLMY FNRTS LPWQGLKAA TKKQK YEKI SE 171 KNLTGTARYAS INTHLGI EQSRRDDLESLGYVLMY FNLGSLPWQGLKAATKRQK YERI SE 171 KNLTGTARYAS INTHLGIEQSRRDDLESLGYVLMYFNLGS LPWQGLKAATKRQK YERI SE 171 KNLTGTARYAS INTHLGIEQSRRDDLESLGYVLMYFNLGS LPWQGLKAATKRQK YERI SE 214 KSLT GTARYMS INTHLGKEQSRRDDLEALGHMFMYFLRGS LPWQGLKADTLKERYQKIGD

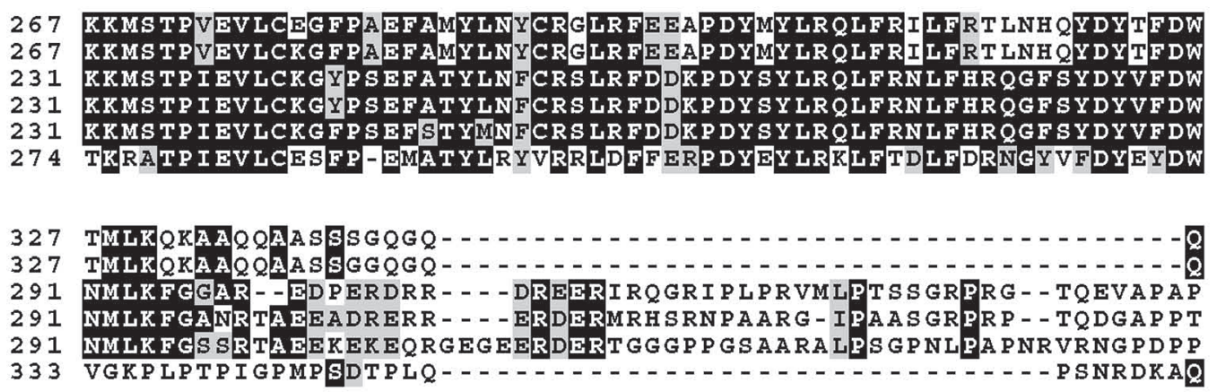

347 AQTPT- 347 AQTPT343 PLT PDSH T - - . - . - - MERERKVS MR LHR GA PVNVSSS DLT GRQDCSRI S T SQA H 344 PLTPTSHTANT - - SSPRPVT GMERERKVSMR LHRGA PVNVSSSDLTGRQDTSRMSTSQNS 351 SSTPASR VPQS GNASPRA GR GAERERRVCLRLHR GA PANASP - DL P LRHDQIRITP PQVS 360 PQTKNQVMS TTN-...-.-GEVNTDDPTAGHSNAPITAPAEVEVADDTKCCCFFKRRK

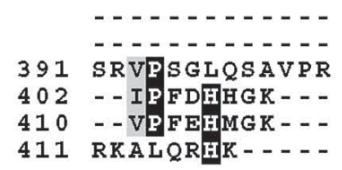

Fig. 2: Amino acid sequence alignment of zebrafish CK1 isoforms. Identical and similar amino acids are indicated by black and gray backgrounds, respectively. The zebrafish CK1 amino acid sequences were compared with human CK1 alpha subunit. 


\section{Expression of CK1 mRNA}

\section{RT-PCR analysis}

We studied the zebrafish CK1 cloned genes at mRNA level by semi-quantitative PCR using zebrafish $\beta$-actin expression as control (Fig. 3). We used specific primers for each gene. Alternative splicing of two exons (called $\mathrm{L}$ and $\mathrm{S}$ ) has been described

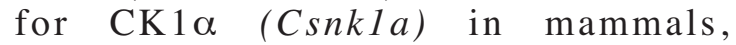
producing four different $\mathrm{CK} 1 \alpha$ spliced variants (CK $1 \alpha, \quad \mathrm{CK} 1 \alpha \mathrm{S}, \quad \mathrm{CK} 1 \alpha \mathrm{L}$, CK $1 \alpha$ LS) (Burzio et al., 2002). In zebrafish, RT-PCR detected the same spliced variants for CK $1 \alpha$ mRNA previously described in mammals (Zhang et al., 1996; Green and Bennet, 1998; Yong et al., 2000; Burzio et al., 2002). However the expression levels of these spliced variants are significantly different. Both CK $1 \alpha$ and $\mathrm{CK} 1 \alpha \mathrm{S}$, the shortest spliced isoforms, have a maternal and zygotic expression component. CK $1 \alpha$ is expressed during the whole embryonic and larval development (Fig. 3). CK $1 \alpha \mathrm{S}$ is progressively induced during embryonic development. Low levels of this mRNA are detected in the early stages of zebrafish development (Fig. 3: compare 3 hpf with 12 hpf). On the contrary, CK $1 \alpha \mathrm{L}$ expression decreases with the progress of embryo development (Fig. 3: compare 3 hpf with 72 hpf). Finally, CK $1 \alpha$ LS expression is slight during zebrafish development. A weak increment in the expression level of this spliced variant could be detected between 9 and $24 \mathrm{hpf}$ (Fig. 3). The other members of the CK1 family gene do not show alternative splicing at least in the embryonic and larval development stages. CK1e (Csnkle) is the only gene whose expression does not show a maternal component. Its expression is induced after 12 hpf. (Fig. 3). The other CK1 isoforms are expressed in all the stages analyzed. We identified two isoforms of human CK1 $\delta$ (Csnklda and Csnkldb). Both genes have maternal and zygotic expression and probably arose by genomic duplication in teleost fish (Chen et al., 2004). Finally $\mathrm{CK} 1 \gamma-2 \mathrm{a}(\mathrm{Csnk} \lg 2 a)$ is expressed in all the stages analyzed in our study.

\section{Expression patterns of CK1 mRNAs}

We will now describe the expression patterns of the five different CK1 mRNAs detected by in situ hybridization during the first 48 hours of zebrafish embryo development.

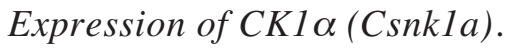

We studied the gene expression pattern of the CK1 $\alpha$ (Csnkla) gene. Because we designed a probe of the 3'UTR region of this gene, in addition we simultaneously detected the four CK $1 \alpha$ species generated by alternative splicing. mRNA in situ hybridization revealed a ubiquitous expression in early stages of development (Fig. 4: A-E). At $17 \mathrm{hpf}$ and $24 \mathrm{hpf}$ the $\mathrm{CK} 1 \alpha$ transcript is detected in brain structures and somites (Fig. $4 \mathrm{D}$ and E). After $24 \mathrm{hpf}$ the expression becomes restricted to encephalic structures and at 30 hpf (data not shown) a weak signal is detected in the pectoral fin bud. The CK1 $\alpha$ mRNA expression in the pectoral fin bud is clearly observed at $42 \mathrm{hpf}$ and thereafter (Fig. 4 F, N, O and R). At 48 hpf the transcript was detected in forebrain, midbrain, retina, lens and also in the primordial pharyngeal arches (mandibular and hyoid archs) (Fig. $4 \mathrm{~N}$ and $\mathrm{O}$ ). Because at $24 \mathrm{hpf}$ the $\mathrm{CK} 1 \alpha$ transcript is detected in the whole embryo, paraffin cross-sections and longitudinal sections of embryos were made. It was very surprising that the $\mathrm{CK} 1 \alpha$ expression is not uniformly detected through the cross-sections of the embryos (Fig. $4 \mathrm{G}$, $\mathrm{H}, \mathrm{I})$. CK1 $\alpha$ expression was detected in the lens and the retina of the embryo eye (Fig. 4 $\mathrm{G}$ and $\mathrm{H}$ ). A more careful analysis of the cross- and longitudinal sections shows that the $\mathrm{CK} 1 \alpha$ transcript is more highly expressed toward the periphery than in the medial region of the sectioned embryo tissue (see arrow heads in Fig. $4 \mathrm{G}, \mathrm{H}$ and I). In the caudal region of the brain the $\mathrm{CK} 1 \alpha$ transcript is strongly expressed toward the ventral lateral side of the neural tube (Fig. 4 $\mathrm{J}, \mathrm{K}, \mathrm{L}$ and $\mathrm{M}$ ). It is also possible to detect a very thin layer of $\mathrm{CK} 1 \alpha$ expression in the medial region of the neural tube (see arrow head in Fig. $4 \mathrm{~J}, \mathrm{~K}$. L and M). This gene is 

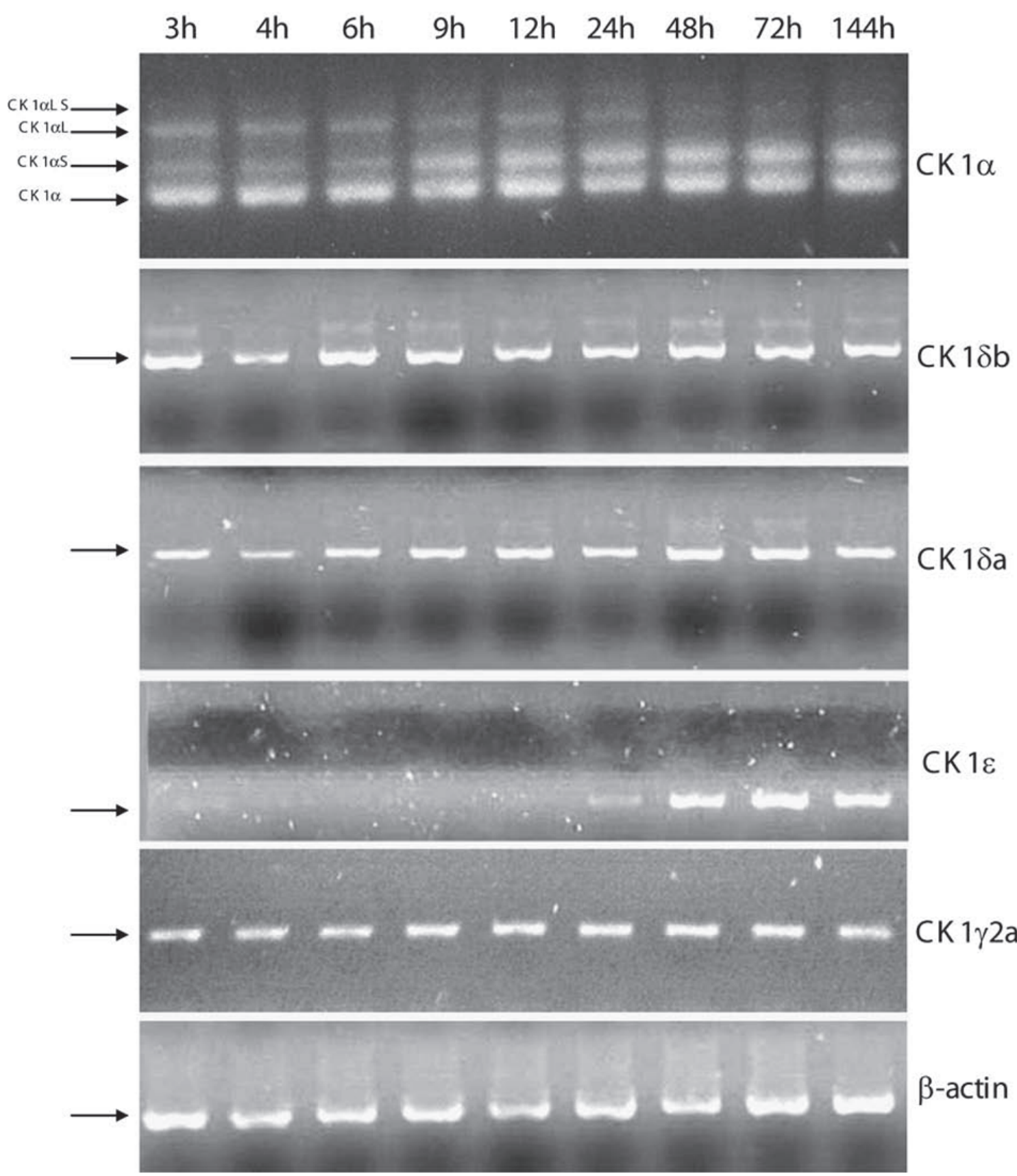

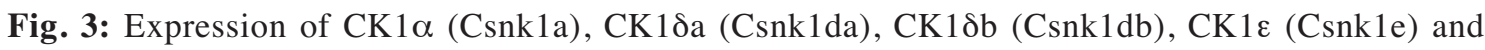
CK1 $\gamma 2 \mathrm{a}$ (Csnk1g2a) at different stages of development as assayed by RT-PCR from total RNA prepared from the indicated stages. CK $1 \delta b, C K 1 \delta a, C K 1 \gamma-2$ are expressed in all the stages analyzed. CK $1 \varepsilon$ shows only a zygotic expression. It is expressed after $12 \mathrm{hpf}$. RT-PCR for the four spliced variants of CK1 $1 \alpha$ were also made: CK $1 \alpha, \mathrm{CK} 1 \alpha \mathrm{L}, \mathrm{CK} 1 \alpha \mathrm{S}$ and CK1 $1 \mathrm{LS}$. These four variants are also expressed at different levels in all the stages analyzed (see text). As an internal control, expression of $\beta$-actin was assessed in the same samples (lower panel). 


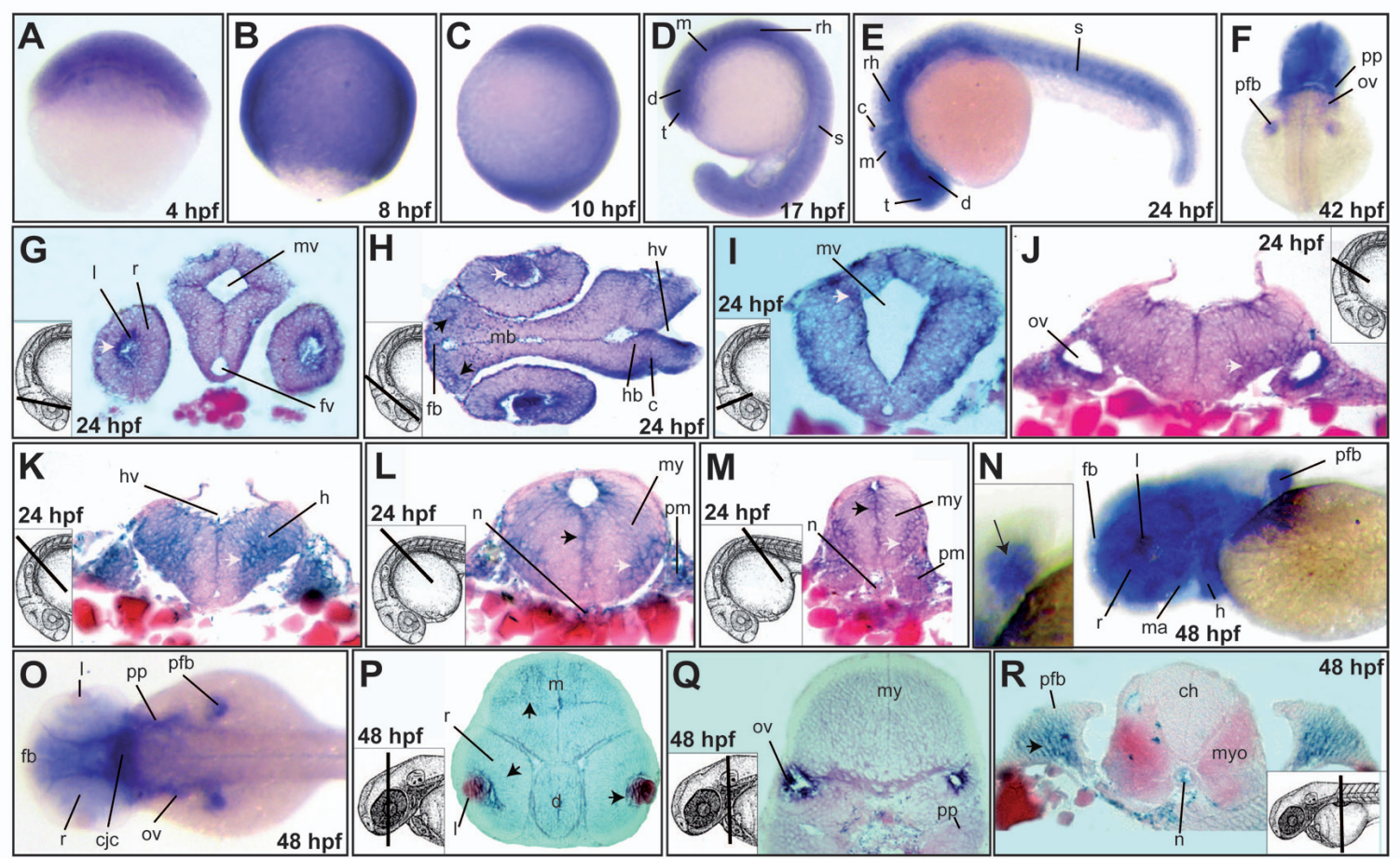

Fig. 4: Whole-mount in situ hybridization for CK1 $\alpha$. Expression of CK1 $1 \alpha$ mRNA was analyzed at the indicated developmental stages. In stages between 4 and $17 \mathrm{hpf}, \mathrm{CK} 1 \alpha$ is expressed at very high levels and ubiquitously (A, B, C, D). At $24 \mathrm{hpf}$ the CK1 $\alpha$ gene is expressed in the whole embryo (E). At $42 \mathrm{hpf}$ the $\mathrm{CK} 1 \alpha$ expression is partly restricted to the cephalic region and pectoral fin bud (F). At $48 \mathrm{hpf}$ the CK1 $\alpha$ expression is observed in the cephalic region, jaw (h and $\mathrm{m}$ ) and pectoral fin buds ( $\mathrm{N}$ and $\mathrm{O}$ ). CK1 $\alpha$ is expressed in the mandibular and hyoid arches $(\mathrm{N})$ of the jaw cartilage in formation. In the inset of $\mathrm{N}$ a detail of $\mathrm{CK} 1 \alpha$ in the pectoral fin bud is shown (this expression is restricted to mesenchymal cells: black arrow). Paraffin cross-sections of embryos were made at $24 \mathrm{hpf}(\mathrm{G}, \mathrm{H}, \mathrm{I}, \mathrm{J}, \mathrm{K}, \mathrm{L}$ and $\mathrm{M})$ and $48 \mathrm{hpf}(\mathrm{P}, \mathrm{Q}$ and $\mathrm{R})$. mRNA expression of CK $1 \alpha$ is ubiquitously observed in the anterior region of the zebrafish brain $(\mathrm{G}, \mathrm{H}$ and $\mathrm{I})$. In the posterior brain $\mathrm{CK} 1 \alpha$ is detected at the borders of the brain tissue (white arrowhead in $\mathrm{K}, \mathrm{L}$ and $\mathrm{M})$. CK $1 \alpha$ expression is detected in the eye lens $(\mathrm{G})$ and the otic vesicle (J). At $48 \mathrm{hpf}$ CK $1 \alpha$ expression is detected in the brain (P and $\mathrm{Q}$ ) and otic vesicle $(\mathrm{Q})$. In the pectoral fin bud CK $1 \alpha$ is restricted to the proximal region (R). Abbreviations: h, hyoid arch; ma, mandibular arch; d, diencephalon; c, cerebellum; ch, caudal hindbrain; cjc, condensing jaw cartilage; fb, forebrain; $\mathrm{fv}$, forebrain ventricle; hb, hindbrain; hv, hindbrain ventricle; l, lens; $\mathrm{m}$, mesencephalon; mb, midbrain; mv, midbrain ventricle; my, mylencephalon, myo, myotome; n. notochord; ov, otic vesicle; r, retina; rh, rhombomeres; pfb, pectoral fin bud; pm, paraxial mesoderm; pp, pharyngeal pouch; s, somites, t, telencephalon.

also expressed in the region surrounding the otic vesicle (Fig. $4 \mathrm{~J}$ ). To confirm the CK1 $\alpha$ gene expression pattern previously observed at $48 \mathrm{hpf}$, paraffin cross-sections were made. Like the expression observed in crosssections of embryos at $24 \mathrm{hpf}$, the CK1 $\alpha$ transcript is not uniformly expressed troughout the embryo brain. This gene is strongly expressed in the lens and the otic vesicle (Fig. $4 \mathrm{P}$ and $\mathrm{Q}$ ) and slightly in retina, mesencephalon, diencephalon and myelencephalon (Fig. 4 P and Q). The CK1 $\alpha$ expression detected in the pectoral fin by whole mount in situ hybridization was confirmed by cross-section of the embryos. In this case the expression was restricted to the basal mesenchymal component of the pectoral fin bud (Fig. 4 R). 
We conclude that the expression pattern of CK $1 \alpha$ mRNA is ubiquitously expressed in early stages of the development. After 24 hpf the expression is limited to the cephalic structures and pectoral fin bud. Cross and longitudinal embryo sections made at 24 and $48 \mathrm{hpf}$ indicate that $\mathrm{CK} 1 \alpha$ expression is not uniform and it seems that it is concentrated at some cell clusters in the brain and the neural tube (Fig. $4 \mathrm{H}$ and L).

\section{Expression of CK1E(Csnkle)}

The CK1 $1 \varepsilon$ expression pattern is different from that observed with $\mathrm{CK} 1 \alpha$. CK $1 \varepsilon$ is not detected before $12 \mathrm{hpf}$ and its expression is restricted to the brain (data not shown and Fig. 5A). At $24 \mathrm{hpf}$ CK $1 \varepsilon$ expression is detected in the diencephalon, telencephalon, eye, tectum, mesencephalon, cerebellum, rhomboencephalon and otic vesicles (Fig. 5 B). At 30 hpf CK $1 \varepsilon$ expression is detected in the tegmentum and the otic vesicles of the zebrafish embryo (Fig. 5 F). At 48 hpf the CK1ع is restricted to the eyes (retina and lens), tegmentum, myelencephalon and otic vesicles (Fig. $5 \mathrm{G}$ and I). A very feeble expression of this gene is detected in the notochord (Fig. $5 \mathrm{G}$ inset). To obtain a more detailed information on zebrafish CK $1 \varepsilon$ expression, cross- and longitudinal sections were made at 24 and $48 \mathrm{hpf}$ and the CK1 1 expression studied. At $24 \mathrm{hpf}$ the expression is detected in cerebellum, diencephalon, telecephalon and retina (Fig. 5 C). A remarkably strong CK1E expression surrounds the hindbrain and the midbrain ventricles (Fig. $5 \mathrm{C}$ and D). The otic vesicle CK1E expression was confirmed by crosssection (Fig. 5 E). Like the CK1 1 mRNA levels detected around ventricles in the brain, a robust expression is detected surrounding the otic vesicles (Fig. 5 E). At $48 \mathrm{hpf}$ cross section experiments display strong expression in the tegmentum, retina in the eye, myelencephalon and otic vesicle (Fig. $5 \mathrm{H}, \mathrm{J}$ and $\mathrm{K}$ ). $\mathrm{CK} 1 \varepsilon$ expression in tegmentum and myelencephalon is confirmed by longitudinal section of the zebrafish embryos (Fig. 5 L). We conclude that $\mathrm{CK} 1 \varepsilon$ mRNA expression does not have a maternal component and it is restricted to cephalic structures during zebrafish development.

\section{Expression of CK $1 \gamma$-2a (Csnk $1 g 2 a)$}

The CK $1 \gamma-2$ a expression is very similar to the one observed with CK $1 \alpha$. This gene is maternally expressed and also shows a ubiquitous expression in early stages of the zebrafish development (Fig. 6 A, B. C). At $17 \mathrm{hpf}$ the $\mathrm{CK} 1 \gamma-2 \mathrm{a}$ mRNA is detected in telencephalon, diencephalon, mesencephalon, rhombomeres and somites (Fig. 6 D). At 24 hpf CK $1 \gamma-2 \mathrm{a}$ is restricted to cephalic structures being detected in telencephalon, diencephalon, cerebellum and rhombomeres (Fig. 6 E). Crosssections of zebrafish embryos at $24 \mathrm{hpf}$ were made (Fig. 6 F, G, H, I and J). A robust expression of this gene is detected in lens and retina and also in the regions of the diencephalon and midbrain that surround the fore- and midbrain ventricles (Fig. $6 \mathrm{~F}, \mathrm{G}$ and $\mathrm{H}$ ). Towards the posterior region of the zebrafish embryo, the $\mathrm{CK} 1 \gamma$ 2 expression seems more uniform. It is strongly observed around the hindbrain ventricle and the otic vesicle (Fig. $6 \mathrm{I}$ and J). At $48 \mathrm{hpf}$ the CK $1 \gamma-2 \mathrm{a}$ mRNA expression is detected in the forebrain, eye, midbrain, hindbrain and pectoral fin bud (Fig. $6 \mathrm{~K}$ and L). Cross-section experiments of embryos fixed and stained at $48 \mathrm{hpf}$ indicate that $\mathrm{CK} 1 \gamma-2 \mathrm{a}$ is uniformly expressed through the mesencephalon and diencephalon, also detecting expression in the lens and the retina (Fig. $6 \mathrm{M}$ ). In the posterior area of the brain it is also possible to observe a regular expression of $\mathrm{CK} 1 \gamma-2 \mathrm{a}$ throughout the myelencephalon (Fig. $6 \mathrm{M})$. CK $1 \gamma-2 \mathrm{a}$ is strongly expressed in the otic vesicle and the pectoral fin bud (Fig. $6 \mathrm{~N}$ and $\mathrm{O}$ ). In the pectoral fin bud, CK $1 \gamma-2 \mathrm{a}$ mRNA is localized in the proximal mesenchymal tissue. It is not expressed in the borders or in the distal region of the bud (Fig. $6 \mathrm{O}$ ). We conclude that CK $1 \gamma-2 \mathrm{a}$ is ubiquitously expressed in early zebrafish development. After $17 \mathrm{hpf}$ the expression of this gene is restricted to the cephalic structures. Crosssection experiments indicate that $\mathrm{CK} 1 \gamma-2 \mathrm{a}$ is uniformly expressed in the brain tissue. 


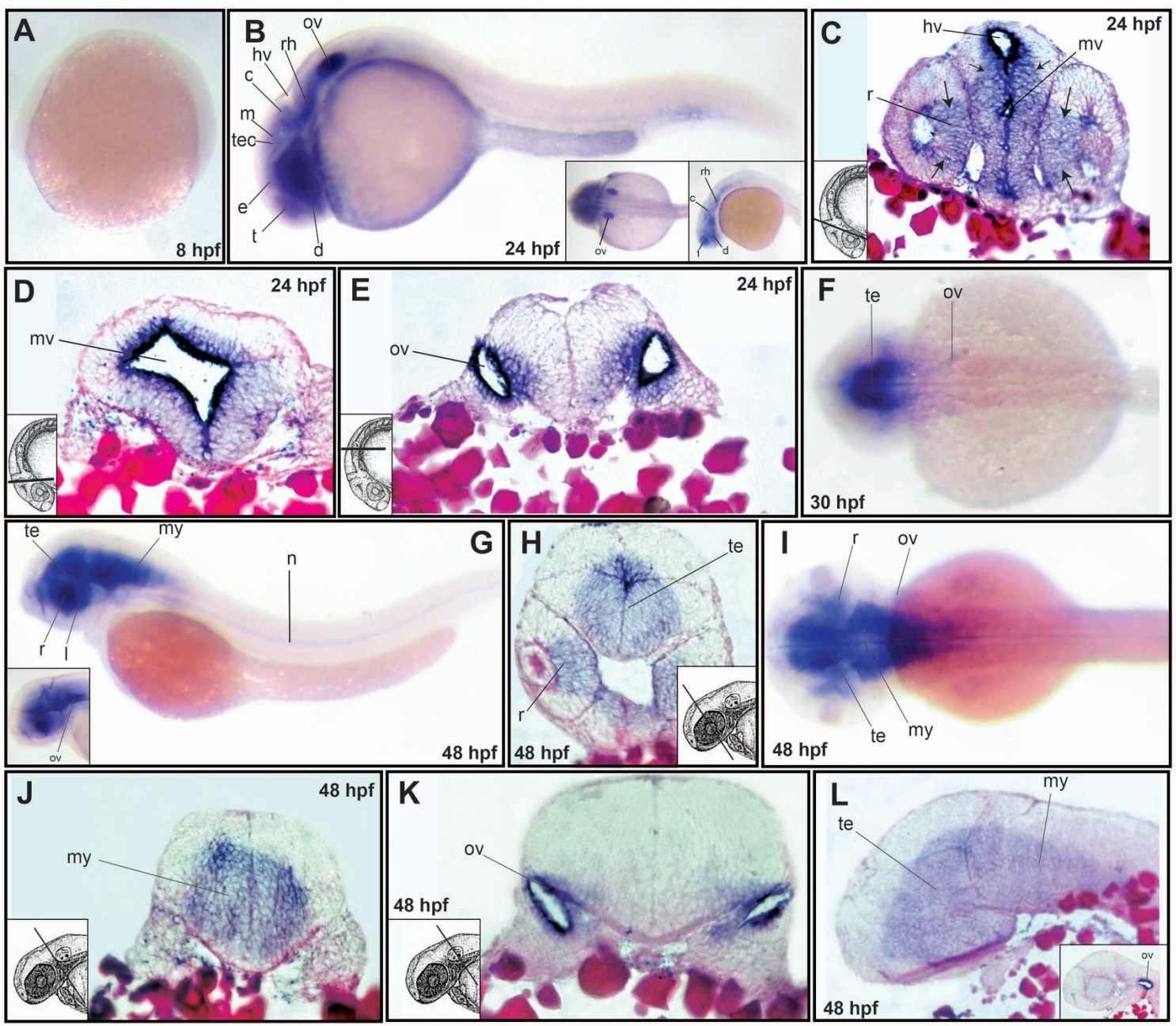

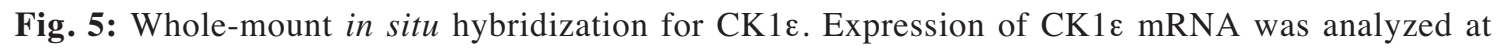
the indicated developmental stages. At $8 \mathrm{hpf} \mathrm{CK} 1 \varepsilon$ is not detected (A). At 24 and CK1 $1 \varepsilon$ is restricted to the cephalic structures: telencephalon, diencephalon and epiphysis in forebrain, tectum in mesencephalon, cerebellum and rhombomeres in hindbrain (B and inset). CK1 $\varepsilon$ is also detected in

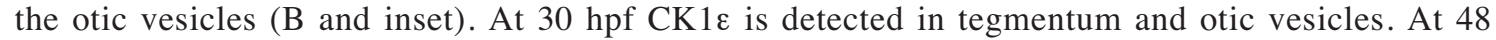
hpf CK $1 \varepsilon$ is expressed in lens, retina, tegmentum, myelencephalon, otic vesicle and notochord (G and I). Paraffin cross-sections of embryos were made at $24 \mathrm{hpf}(\mathrm{C}, \mathrm{D}$ and $\mathrm{E})$ and $48 \mathrm{hpf}(\mathrm{P}, \mathrm{Q}$ and $\mathrm{R})$. At $24 \mathrm{hpf}$ CK1ع expression is detected in regions surrounding the midbrain ventricle (C, D) and hindbrain ventricle $(\mathrm{C})$. Those areas include cerebellum, midbrain, diencephalon, telencephalon and retina (region limited by arrows in $\mathrm{C}$ ). CK1 $1 \varepsilon$ is also expressed in regions surrounding the otic vesicles (E). At 48 hpf CK1 $1 \varepsilon$ is detected in retina, tegmentum $(\mathrm{H})$, myelencephalon $(\mathrm{J})$ and otic vesicles (K). CK1 $1 \varepsilon$ expression in tegmentum and myelencephalon is confirmed by longitudinal sections of the zebrafish embryos (L). Abbreviations: c, cerebellum; d, diencephalon; hv, hindbrain ventricle; 1 , lens; m, mesencephalon; mv, midbrain ventricle; my, myelencephalon; $\mathrm{n}$, notochord; ov, otic vesicle; r, retina; rh, rhombomeres; t, telencephalon; tec, tectum; te, tegmentum. 


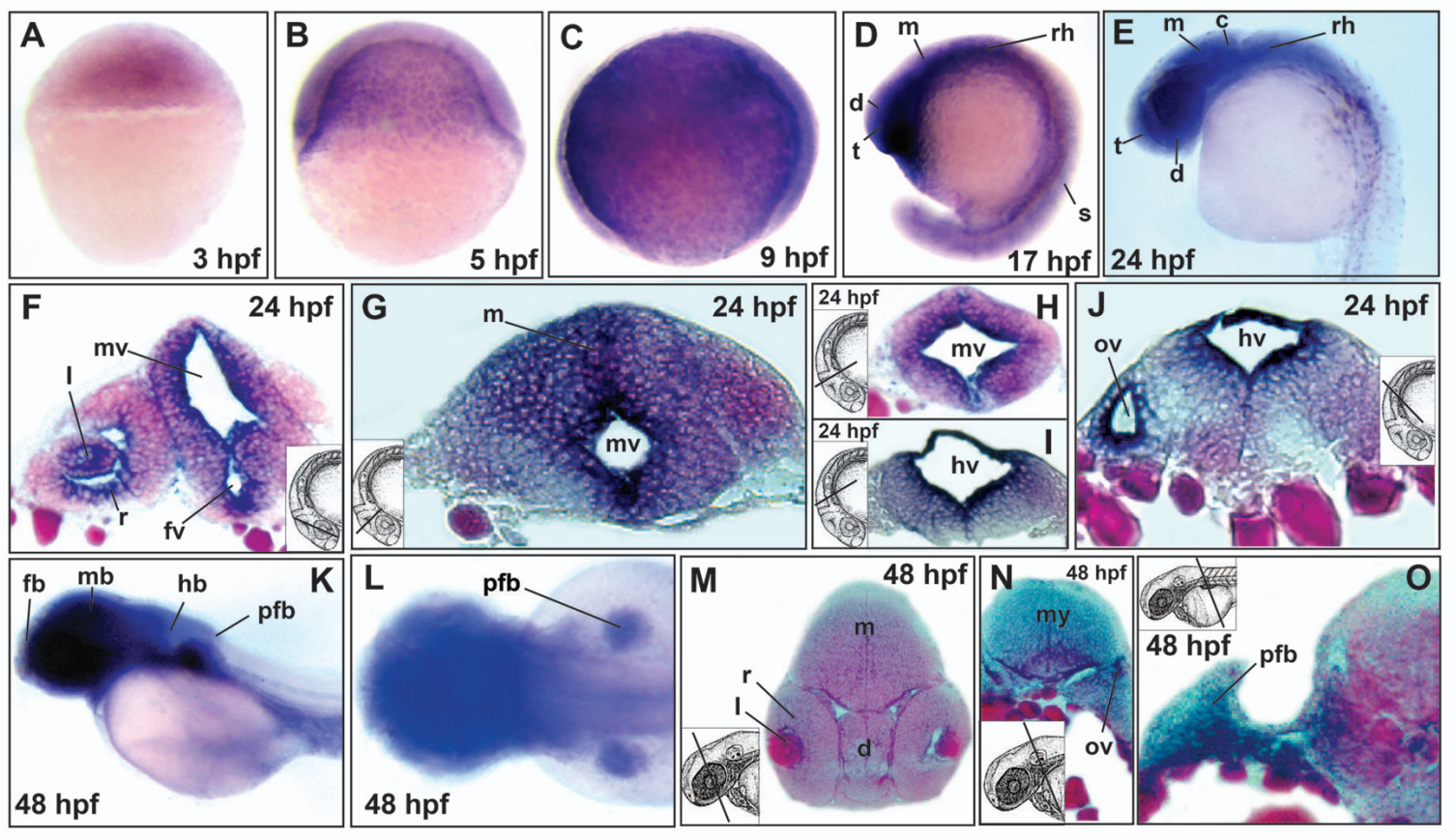

Fig. 6: Whole-mount in situ hybridization for CK1 $\gamma-2 \mathrm{a}$. Expression of CK1 $\gamma-2 \mathrm{a}$ mRNA was analyzed at the indicated developmental stages. CK1 $1 \gamma-2$ is ubiquitously expressed in earlier stages of the zebrafish development (A, B, C and D). At 24 and $48 \mathrm{hpf}$ CK $1 \gamma-2 \mathrm{a}$ is detected in cephalic structures of the zebrafish embryo (E, K and L). Paraffin cross-sections made at 24 hpf show a strong expression in retina, lens and the surrounding tissue of the forebrain ventricle, midbrain ventricle and hindbrain ventricle (F, G, H, I and J). Cross-sections made at the midbrain level show a ubiquitous CK $1 \gamma$-2a expression in the entire tissue analyzed ( $\mathrm{I}$ and $\mathrm{J}$ ). CK1 $\gamma-2 \mathrm{a}$ is also expressed in otic vesicles (J). Paraffin cross-sections made at $24 \mathrm{hpf}$ shows a uniform CK1 $\gamma$ - 2 a expression in the midbrain $(\mathrm{M})$ and hindbrain $(\mathrm{N})$ tissue. $\mathrm{CK} 1 \gamma-2 \mathrm{a}$ is detected in lens and retina $(\mathrm{M})$, otic vesicles (N) and the proximal region of the pectoral fin bud (O). Abbreviations: c, cerebellum; d, diencephalon; fb, forebrain; fv, forebrain ventricle; hb, hindbrain; hv, hindbrain ventricle; 1 , lens; $\mathrm{m}$, mesencephalon; mb, midbrain; mv, midbrain ventricle; my, myelencephalon; ov, otic vesicle; pfb, pectoral fin bud; $r$, retina; rh, rhombomeres, $t$, telencephalon.

Expression of $C K 1 \delta a$ and $C K 1 \delta(C s n k 1 d a$ and $C \operatorname{snk} 1 \mathrm{db}$ )

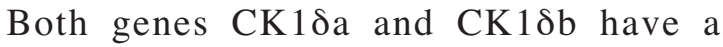
maternal and zygotic component in their expression (Fig. 7 A, 8 A and data not shown). Both genes are also ubiquitously expressed in zebrafish embryos until $8 \mathrm{hpf}$ (Figs. 7 A, B, C, D and 8 A, B, C, D). However $\mathrm{CK} 1 \delta b$ displays a very significant

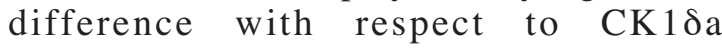
expression at $8 \mathrm{hpf}$. In this stage $\mathrm{CK} 1 \delta \mathrm{b}$ shows a very robust expression in the neural plate (compare Fig. $7 \mathrm{D}$ with $8 \mathrm{C}$ ). To verify that part of the CK $1 \delta$ b expression is related to the neural plate we made

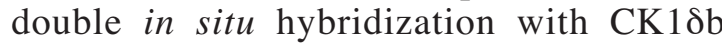
and BMP-2 probes. BMP-2 is expressed in the dorsal part of the zebrafish embryo (Fig. $8 \mathrm{D}$ see white and black arrows). In this case it is possible to detect $\mathrm{CK} 1 \delta \mathrm{b}$ expression (Fig. 8 D, black arrow) over the BMP-2 expression (Fig. 8 D, white arrow). Between 10 and 24 hpf CK1 1 a is expressed in the whole embryo, but this expression is stronger in the cephalic than in the posterior structures (Fig. 7 E, F and G). At 17 and 24 hpf it is possible to detect CK $1 \delta b$ expression in telencephalon, diencephalon, mesencephalon, cerebellum and rhombomeres. Also CK $1 \delta b$ expression is 


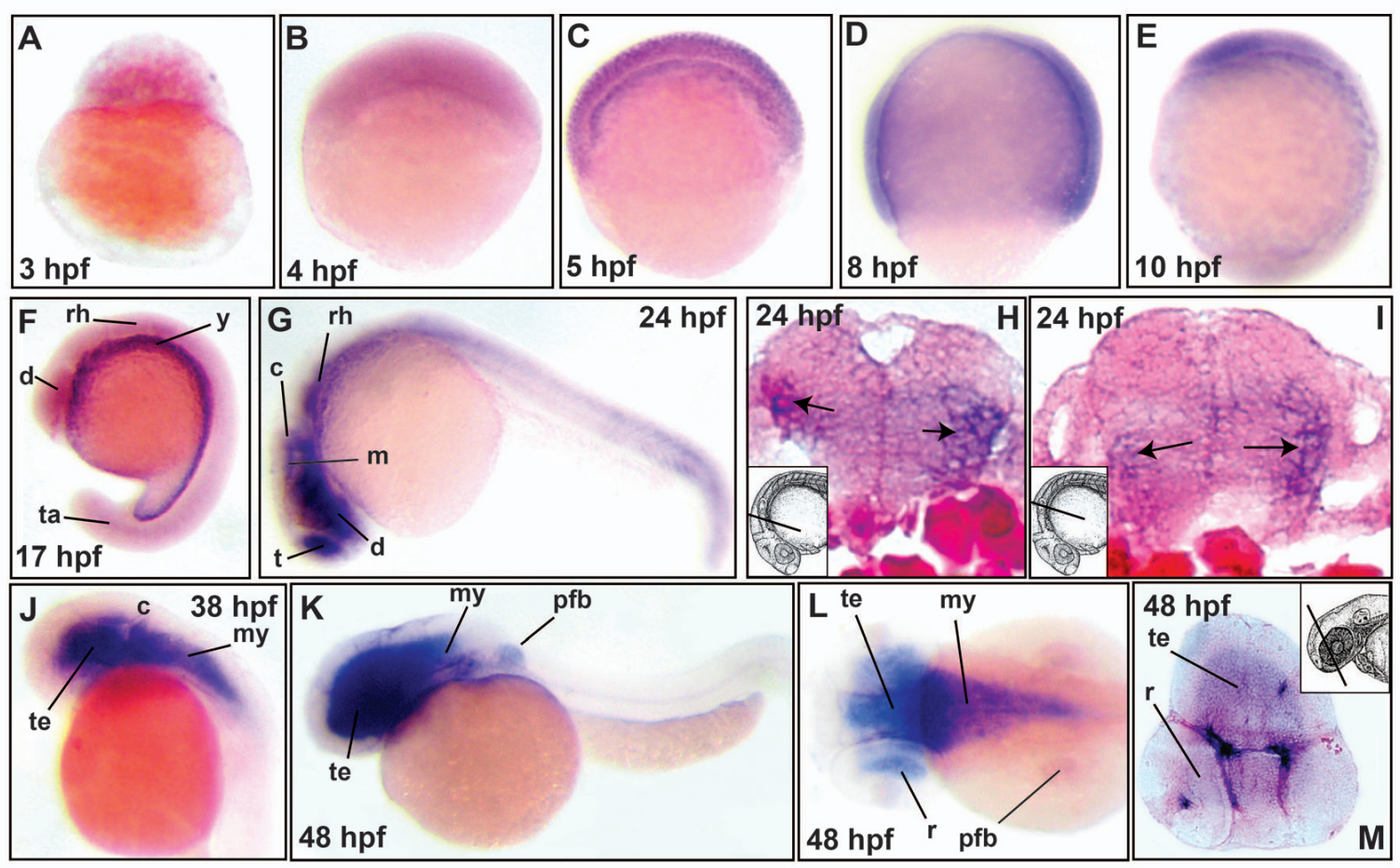

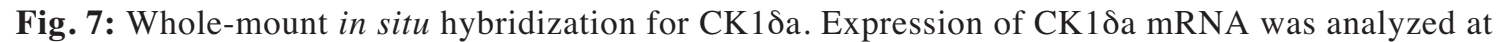
the indicated developmental stages. CK1 $\mathrm{da}$ is ubiquitously expressed in earlier stages of the zebrafish development (A, B, C and D). At 10 hpf CK1 $1 \delta a$ expression is notoriously detected in the cephalic region. A low level of expression is detected in the caudal region of the zebrafish embryos

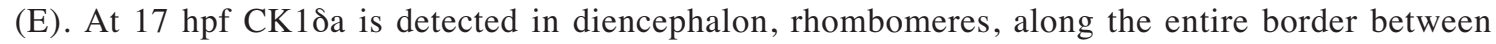
the yolk and the embryo and also in the caudal region of the embryo (tail) (F). At 24 hpf a strong

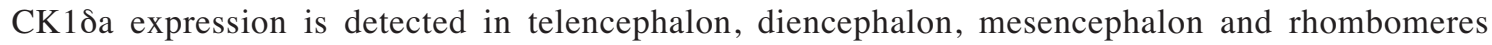
(G). A weaker expression is detected in the somites and the tail of the embryo (G). At 38 and $48 \mathrm{hpf}$

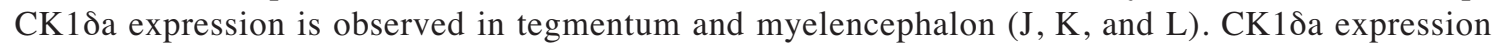
is detected in pectoral fin bud (at low levels) and retina ( $\mathrm{K}$ and $\mathrm{L}$ ). Paraffin cross-sections made at $24 \mathrm{hpf}$ show a medial lateral CK1 $1 \delta$ a expression in the caudal region of the brain (black arrows in $\mathrm{H}$ and J). Paraffin cross-sections made at $48 \mathrm{hpf}$ confirm the CK1ठa expression in tegmentum and retina (M). Abbreviations: c, cerebellum; d, diencephalon, my, myelencephalon; pfb, pectoral fin bud; r, retina; rh, rhombomeres; t, telencephalon; te, tegmentum; ta, tail; y, yolk.

detected in the tail of the embryos (Fig. $7 \mathrm{~F}$ and $\mathrm{G})$. However in the same stages the CK1 $1 \delta$ mRNA expression is detected in cephalic structures: diencephalon, telencephalon, mesencephalon, cerebellum and rhombomeres (Fig. 8 F, G and H). At 38 and $48 \mathrm{hpf} \mathrm{CK} 1 \delta \mathrm{a}$ is expressed in retina, tegmentum and myelencephalon (Fig. 7 I, J and $\mathrm{K})$. A very weak expression is also detected in the pectoral fin bud (Fig. 7 L). At $38 \mathrm{hpf} \mathrm{CK} 1 \delta \mathrm{b}$ is expressed in telencephalon, diencephalon, mesencephalon cerebellum and rhombomeres. This last result implicates that at $38 \mathrm{hpf}$ stage CK1 1 a shows a different expression pattern than CK1 $1 \delta$ b (compare Figs. $7 \mathrm{I}$ with $8 \mathrm{~J}$ ). At $48 \mathrm{hpf} \mathrm{CK} 1 \delta \mathrm{b}$ is expressed in retina, tegmentum, myelencephalon and notochord (Fig. $8 \mathrm{~J}$ and

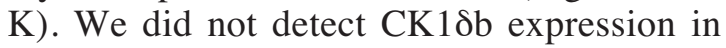
pectoral fin bud (Fig. $8 \mathrm{~K}$ ). At 24 hpf crosssection experiments were made to analyze CK1 $1 \delta$ a expression in the posterior region of

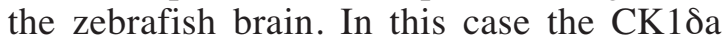
expression is detected in the lateral region of 

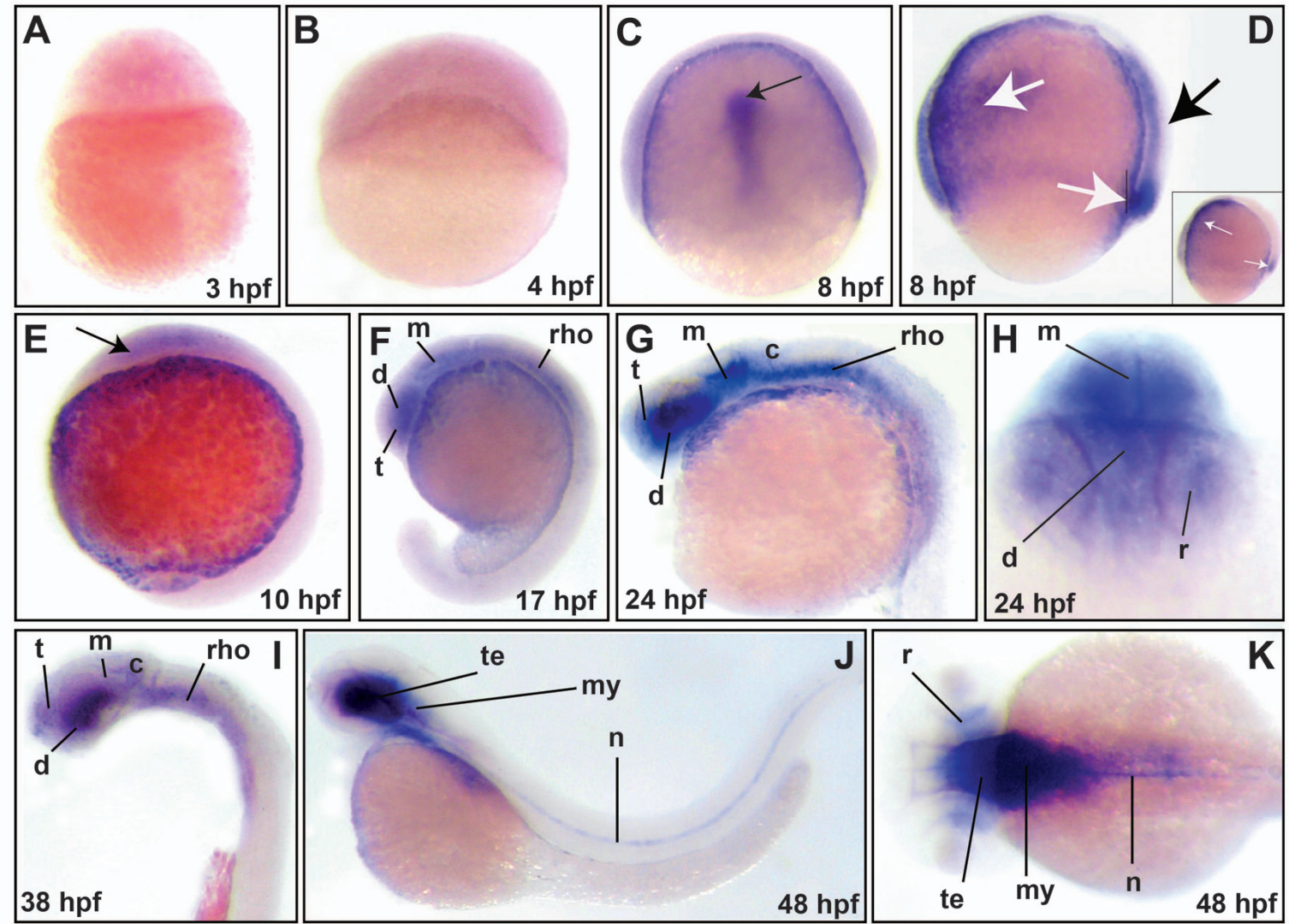

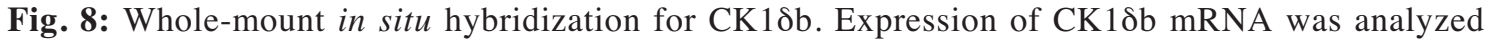
at the indicated developmental stages. CK1 $1 \delta$ is ubiquitously expressed in earlier stages of zebrafish development (A, B, C and D). However, at 8 hpf a very strong expression is detected in the neural plate (dorsal region of the embryos, black arrows in $\mathrm{C}$ and $\mathrm{D}$ ). Double in situ

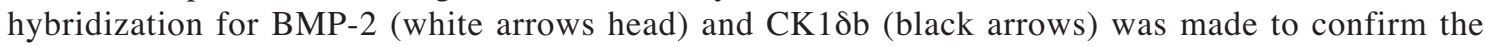
$\mathrm{CK} 1 \delta \mathrm{b}$ in the neural plate of the zebrafish embryos (D). The inset in D, shows the BMP-2 in situ hybridization as a control. In later stages of development ( $\mathrm{E}$ and F) $\mathrm{CK} 1 \delta \mathrm{b}$ expression is restricted to cephalic structures. At 24 and $38 \mathrm{hpf} \mathrm{CK} 1 \delta \mathrm{b}$ expression is detected in telencephalon, retina, diencephalon, mesencephalon, cerebellum and rombhomeres ( $\mathrm{G}$ and $\mathrm{H})$. At $48 \mathrm{hpf} \mathrm{CK} 1 \delta \mathrm{b}$ is detected in tegmentum, myelencephalon and notochord ( $\mathrm{J}$ ad $\mathrm{K})$. Abbreviations: c, cerebellum; $\mathrm{d}$, diencephalon; m, mesencephalon; my, myelencephalon; r, retina; rh, rhombomeres; $\mathrm{t}$, telencephalon; te, tegmentum; n, notochord.

the hindbrain (Fig. $7 \mathrm{H}$ and I, see black arrows). At 48 hpf cross-section experiments made in the anterior region of the brain indicate that $\mathrm{CK} 1 \delta \mathrm{d}$ is expressed in retina and tegmentum (Fig. $7 \mathrm{M}$ ). This last result confirms the CK1 1 a expression pattern observed in whole mount in situ hybridization at $48 \mathrm{hpf}$. We conclude that both CK1 $\delta$ isoforms are expressed in zebrafish embryos but they do not have the same expression pattern. Both genes have maternal and zygotic components of expression and are ubiquitously expressed in early stages. However at $8 \mathrm{hpf}$ CK1 1 b shows expression in the neural plate. At this stage CK1סa is uniformly expressed. Until $24 \mathrm{hpf}$ CK1 1 a is expressed in the whole zebrafish embryo while $\mathrm{CK} 1 \delta \mathrm{b}$ is restricted to the brain. In earlier stages both genes have a relatively similar expression. 


\section{DISCUSSION}

We have cloned five members of the CK1 gene family of the zebrafish and also studied their mRNA expression pattern by semi-quantitative RT-PCR and in situ hybridization during development. This is the first time that a detailed comparison of the expression of CK1 isoforms is directly assessed in a vertebrate system throughout development. We identified in the zebrafish genome one copy for $\mathrm{CK} 1 \alpha$ isoform, one copy for CK $1 \varepsilon$, two gene copies for CK $1 \delta$ isoforms, one copy for CK $1 \gamma-1$ isoform and two gene copies for $\mathrm{CK} 1 \gamma-2$ isoforms. From these seven genes we cloned CK $1 \alpha, \mathrm{CK} 1 \varepsilon$, two cDNAs for CK1 $1 \delta$ and one of the two copies for $\mathrm{CK} 1 \gamma-2$. In zebrafish the existence of two gene copies for one kind of protein is not uncommon. This duplication is probably the direct result of the genomic duplication in teleost fish (Amores et al., 2004). The existence of seven genes coding for members of the CK1 gene family probably indicates a multiplicity of function for those genes during zebrafish development. It is probable that those isoforms carry out redundant functions during development. Of the five CK1 isoforms cloned, only CK1ع does not have maternal expression. The rest have maternal and zygotic expression. CK $1 \alpha$, CK $1 \delta a, C K 1 \delta b$ and CK $1 \gamma-2$ a are ubiquitously expressed in early stages of the zebrafish development. The differential expression pattern of

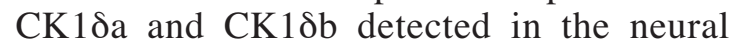
plate is remarkable. In later stages of zebrafish development both CK $1 \delta$ genes and $\mathrm{CK} 1 \varepsilon$ have a similar expression pattern in the brain. One common point in the mRNA expression of the CK1 gene family is their expression in the brain in later stages of development. Although the CK1 gene family is expressed in some common locations in the embryos, they do not exhibit the same expression pattern. Actually, our results indicate that the CK1 genes are differentially expressed during development. Although orthologous genes have been described in several different vertebrate species (Tapia et al., 1994; Zhang et al., 1996; Green and Bennet,
1998; Yong et al., 2000; Burzio et al., 2002), there are no comparative expression studies made during vertebrate development at the mRNA level. Several studies seeking to detect CK1 isoform protein in cell culture and adult tissues of different species have been carried out (Camacho et al., 2001; Kannanayakal, 2006). In Xenopus the $\mathrm{CK} 1 \gamma-1$ and $\mathrm{CK} 1 \gamma-2$ mRNA expression pattern studies during development have been done (Davidson et al., 2005). In comparison to zebrafish $\mathrm{CK} 1 \gamma-2 \mathrm{a}$, mRNA expression for both genes described in Xenopus shows a similar expression throughout development. This last observation probably indicates a similar function for CK1 orthologues in the development of vertebrates.

\section{ACKNOWLEDGEMENTS}

We thank Dr. Catherine Connelly for discussion and critical reading of the manuscript. This work was supported by grants from Millennium Scientific Initiative (ICM P02-050), Fondecyt \# 1040697 to MA and Fondecyt \# 1060441 to AER.

\section{REFERENCES}

AMORES A, SUZUKI T, YAN YL, POMEROY J, SINGER A, AMEMIYA C, POSTLETHWAIT JH (2004) Developmental roles of pufferfish Hox clusters and genome evolution in ray-fin fish. Genome Res 14: $1-10$

BEVER MM, FEKETE DM (2002) Atlas of the developing inner ear in zebrafish. Dev Dyn 223: 536-543

BURZIO V, ANTONELLI M, ALLENDE C, ALLENDE JE (2002) Biochemical and Cellular Characteristics of the four splice variants of protein kinase CK1 from zebrafish (Danio rerio). J Cell Biochem 86: 805-814

CAMACHO F, CILIO M, GUO Y, VIRSHUP DM, PATELA K, KHORKOVA O, STYRENA S, MORSE B, YAO Z, KEESLER GA (2001) Human casein kinase I $\delta$ phosphorylation of human circadian clock proteins period 1 and 2. FEBS Lett 489: 159-165

CHEN WY, JOHN JA, LIN CH, CHANG CY (2002) Molecular cloning and developmental expression of zinc finger transcription factor MTF-1 gene in zebrafish, Danio rerio. Biochem Biophys Res Commun 291: 798-805

CHEN WJ, ORTI G, MEYER A (2004) Novel evolutionary relationship among four fish model system. Trends Genet 20, 424-431

CHENNA R, SUGAWARA H, KOIKE T, LOPEZ R, GIBSON TJ, HIGGINS DG, THOMPSON JD (2003) Multiple sequence alignment with the clustal series of programs. Nucleic Acid Res 31: 3497-3500 
CONG F SCHWEIZER L, VARMUS H (2004) Casein kinase $I \varepsilon$ modulates the signaling specificities of dishevelled. Mol Cell Biol 24: 2000-11

DAVIDSON G, WU W, SHEN J, BILIC J, FENGER U, STANNEK P, GLINKA A, NIEHRS C (2005) Casein kinase 1 gamma couples Wnt receptor activation to cytoplasmic signal transduction. Nature 438: 867-872

HANKS S K, HUNTER T (1995) The eukaryotic protein kinase superfamily: Kinase (catalytic) domain structure and classification. FASEB J 9: 576-596

JOWETT T, LETTICE L, (1994) Whole-mount in situ hybridizations on zebrafish embryos using a mixture of digoxigenin- and fluorescein labelled probes. Trends Genet 10, 73-74

KANNANAYAKAL T J, TAO H, VANDRE D, KURET J (2006) Casein kinase-1 isoforms differentially associate with neurofibrillary and granulovacuolar degeneration lesions. Acta Neuropathol 111: 413-421

KIMMEL CB, BALLARD WW, KIMMEL SR, ULLMANN B, SCHILLING TF (1995) Stages of embryonic development of the zebrafish. Dev Dyn 203: 253-310

KIMURA M (1980) A simple method for estimating evolutionary rate of base substitutions through comparative studies of nucleotide sequences. J Mol Evol 16: 111-120

KUMAR S, TAMURA K, NEI M, (2004) MEGA3: Integrated Software for Molecular Evolutionary Genetics Analysis and Sequence Alignment. Brief Bioinform 5: 150-163

KNIPPSCHILD U, GOCHT A, WOLFF S, HUBER N, LÖHLER J, STÖTER M (2005) The casein kinase 1 family: participation in multiple cellular processes in eukaryotes. Cell Signal 17: 675-689

GREEN CL, BENNETT GS (1998) Identification of four alternatively spliced isoforms of chicken casein kinase I alpha that are all expressed in diverse cell types. Gene 216: 189-195

GROSS S, ANDERSON, R (1998) Casein kinase I: Spatial organization and positioning of a multifunctional protein kinase family. Cell Signal 10: 699-711

HAFFTER P, GRANATO M, BRAND M, MULLINS MC, HAMMERSCHMIDT M, KANE DA, ODENTHAL J, VAN EEDEN FJ, JIANG YJ, HEISENBERG CP, KELSH RN, FURUTANI-SEIKI M, VOGELSANG E, BEUCHLE D, SCHACH U, FABIAN C, NUSSLEINVOLHARD C, 1996. The identification of genes with unique and essential functions in the development of the zebrafish, Danio rerio. Development 123: 1-36

LIU C, LI Y, SEMENOV M, HAN C, BAEG G, TAN Y, ZHANG Z, LIN X, HE XI (2002) Control of $\beta$-catenin phosphorylation/degradation by a dual-kinase mechanism. Cell 108: 837-847
LEE J, CHIE C (2004) When sugars guide axons: insight from heparan sulphate proteoglycan mutants. Nat Rev Genet 5: 923-935

LEWIS K, EISEN J (2003) From cells to circuit: development of the zebrafish spinal cord. Prog Neurobiol 69: 419-449

MACKENZIE NC, BRITO M, REYES AE, ALLENDE ML (2004) Cloning, expression pattern and essentiality of the high-affinity copper transporter 1 (ctr1) gene in zebrafish. Gene 328: 113-120

MARÍN O, BUSTOS V, CESARO L, MEGGIO F, PAGANO M, ANTONELLI M, ALLENDE C, PINNA L, ALLENDE J (2003) Proc Natl Acad Sci USA 100: 10193-10200

PAN Y, BAI C, JOYNER A, WANG B (2006) Sonic hedgehog signaling regulates Gli2 transcriptional activity by suppressing its processing and degradation. Mol Cell Biol 26: 3365-3377

SAITOU N, NEI, M (1987) The neighbor-joining method: a new method for reconstructing phylogenetic trees. Mol Biol Evol 4: 406-425

SAMBROOK, J, FRITSCH, E MANIATIS, T (1989) Molecular Cloning: a Laboratory Manual. 2nd ed. New York. Cold Spring Harbor Laboratory Press

SCHWEITZER, JS, BECKER, C G, SCHACHNER, M BECKER, T (2005) Expression of collapsing response mediator proteins in the nervous system of embryonic zebrafish. Gene Expression Patterns 5: 809-816

TAPIA C, FEATHERSTONE T, GÓMEZ C, TAILLONMILLER P, ALLENDE CC, ALLENDE JE (1994) Cloning and chromosomal localization of the gene coding for human protein kinase CK1. FEBS Lett 349: 307-312

TEMPE D, CASAS M, KARAZ S, BLANCHETTOURNIER M, CONCORDET J (2006) Multisite protein kinase A and glycogen synthase kinase 3 beta phosphorylation leads to Gli3 ubiquitination by SCFbetaTrCP. Mol Cell Biol 26: 4316-4326

VIELHABER, E, VIRSHUP, D (2001) Casein kinase 1: From obscurity to center Stage. Life 51: 73-78

WESTERFIELD, M, (1995) The Zebrafish Book, fourth ed University of Oregon Press, Eugene.

YONG TJ, GAN YY, TOH BH, SENTRY JW (2000) Human CKI alpha (L) and CKI alpha (S) are encoded by both $2.4-$ and $4.2-\mathrm{kb}$ transcripts, the longer containing multiple RNA-destablising elements. Biochim Biophys Acta 1492: 425-433

ZHANG J, GROSS SD, SCHROEDER MD, ANDERSON RA (1996) Casein kinase I $\alpha$ and $\alpha \mathrm{L}$ : Alternative splicing-generated kinases exhibit different catalytic properties. Biochemistry 35: 16319-16327 

